\title{
Tuberculosis/COVID-19 co-infection detected in a single sputum sample using a rapid molecular test
}

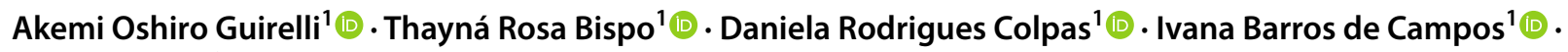 \\ Erica Chimara ${ }^{2}$ - Maria Cecília Cergole-Novella ${ }^{1}$ - Itatiana Ferreira Rodart ${ }^{1}{ }^{1}$.

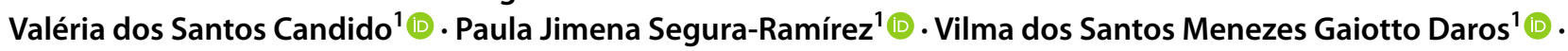 \\ Andreia Moreira dos Santos Carmo ${ }^{1}$ (1)
}

Received: 9 November 2021 / Accepted: 27 December 2021 / Published online: 2 February 2022

(c) The Author(s) under exclusive licence to Sociedade Brasileira de Microbiologia 2022

\begin{abstract}
Tuberculosis (TB) and COVID-19 affect the lungs and are transmitted mainly by aerosols or particles of saliva from infected persons. Clinical similarities between diseases can affect correct diagnosis. Individuals belonging to the population deprived of liberty (PDL) are at increased risk of contagion due to precarious sanitary conditions and overcrowded environments. A variety of specimens may be suitable for the diagnosis of COVID-19, using molecular diagnostic techniques; however, there is little data on the analysis of sputum samples with the Xpert Xpress SARS-CoV-2® for the diagnosis of COVID-19, especially in this population group. The present study reports a case of TB and COVID-19 co-infection detected in sputum from an individual belonging to the PDL. For the detection, it used the GeneXpert platform (Cepheid, USA). Mycobacterium tuberculosis complex (MTC) was detected using the Xpert MTB/RIF Ultra ${ }^{\circledR}$ cartridge and SARS-CoV-2 was detected using the Xpert Xpress SARS-CoV-2® cartridge. The genes IS6110 and IS1081 were detected within 80 min indicating the presence of MTC, with no mutations related to resistance to rifampicin. The SARS-CoV-2 E and N2 genes were detected within $45 \mathrm{~min}$. The result was confirmed by RT-qPCR with detection of E, N, and RdRP/S genes in the sputum and nasopharyngeal (NP) specimens. Rapid diagnoses that allow the identification and differentiation of such diseases are important for adequate epidemiological surveillance, isolation of infected individuals, and interruption of the transmission chain. Using the GeneXpert platform, specimens can be tested as soon as they are received, without the need for prior preparation. The US Food and Drug Administration has issued emergency authorization for the use of the Cepheid Xpert Xpress SARS-CoV-2 for the rapid detection of SARS-CoV-2 using specimens from a NP or nasal wash/aspirate. The case presented here gains an innovation with the use of the sputum to COVID-19 diagnosis.
\end{abstract}

Keywords Co-infection · COVID-19 $\cdot$ SARS-CoV-2 $~$ Tuberculosis, population deprived of liberty, vulnerable population

\section{Introduction}

Coronavirus 2019 disease (COVID-19) has caused a global pandemic of high transmissibility [1]. Tuberculosis (TB) is considered a disease that predominantly affects the less favored and vulnerable social classes, such as people living with HIV/AIDS, individuals being treated with immunosuppressants, people in constant contact with individuals with

Responsible Editor: Fernando R. Pavan

Andreia Moreira dos Santos Carmo

amscarmo@yahoo.com.br

Extended author information available on the last page of the article resistant tuberculosis, children below 5 years old, health professionals, immigrants, elderly, homeless population, and population deprived of liberty and living in a community environment [2]. Since the beginning of the COVID-19 pandemic, concomitant cases of tuberculosis and COVID-19 have been reported [3-5], generating a growing number of studies trying to elucidate the interactions between $\mathrm{Myco}$ bacterium tuberculosis (MTB) and SARS-CoV-2. Some case reports point to a worsening of respiratory symptoms in individuals co-infected with TB/COVID-19 [4, 6].

Patients with TB and COVID-19 may be at greater risk of disease severity and death when compared to those with COVID-19 alone [4]. Sy et al. (2020) reported a risk of death 2.17 times greater in patients with TB/COVID-19 
co-infection than in patients with COVID-19 alone, and the co-infection reduces the chance of COVID-19 recovery by $25 \%$ [3]. It has been reported that individuals with pulmonary sequelae caused by COVID-19 may be at increased risk of developing tuberculosis in the future [7]. Associated with this scenario of increased risk of complications to which populations of individuals in vulnerable conditions are subject, the need for early detection of the association between both diseases is highlighted for the proper management and isolation of affected individuals $[6,8]$. This study reports a case of TB/COVID-19 co-infection in an individual belonging to the population deprived of liberty.

\section{Materials and methods}

The present analysis is part of a research project aimed to standardize the Xpert Xpress SARS-CoV-2® assay in sputum samples from vulnerable populations, supported by the São Paulo State Research Support Foundation (FAPESP). The sputum sample and the nasopharyngeal secretion sample were obtained simultaneously. Both samples were delivered to the laboratory on the same day when they were taken. For the investigation of the M. tuberculosis complex (MTC) in the sputum sample, the Xpert MTB/RIF Ultra ${ }^{\circledR}$ cartridge (Cepheid, USA) from the GeneXpert platform was used. Briefly, a one $\mathrm{mL}$ sputum sample was diluted with $2 \mathrm{~mL}$ of reagent provided by the manufacturer. The mixture was shaken on a vortex mixer for at least $10 \mathrm{~s}$ and incubated at room temperature for $15 \mathrm{~min}$ until complete liquefaction. Two milliliters of this solution was transferred to the cartridge and proceeded to test, according to the manufacturer's instructions. This test simultaneously detects the presence of MTC and rifampicin resistance genes [10, 11].

At the same time, the culture in liquid medium was performed using an automated system BACTEC MGIT 960® Mycobacteria Growth Indicator Tube (Becton \& Dickinson, USA). For this purpose, the sample was treated by the modified Petroff's method [15]. To an approximate volume of two $\mathrm{mL}$ of sputum, an equal volume of $1 \mathrm{~N} \mathrm{NaOH}$ solution was added, containing phenol red indicator for fluidization and decontamination of the sample. The tubes containing the fluidized samples were homogenized and placed in a bacteriological incubator at $36^{\circ} \mathrm{C} \pm 1^{\circ} \mathrm{C}$ for $15 \mathrm{~min}$ and then centrifuged at 3,000 $\times g$ for $15 \mathrm{~min}$. To adjust the $\mathrm{pH}, 1 \mathrm{~N}$ $\mathrm{HCl}$ was added to the sediment until it turned yellow. Then, a sterile neutralizing solution was added until it turned pink in color. After this process, an aliquot of $0.5 \mathrm{~mL}$ was seeded in an MGIT liquid medium containing $800 \mu \mathrm{L}$ of enrichment solution and antibiotics (Becton \& Dickinson, USA). The tubes were incubated in the automated BACTEC MGIT 960 $\mathrm{TB} \circledast$ system, with automatic growth monitoring every 60 $\mathrm{min}$. Growth in liquid medium was confirmed for the presence of acid-fast bacilli (AFB) by a culture smear stained
Fig. 1 Xpert MTB/RIF Ultra ${ }^{\circledR}$ (Cepheid) with sputum sample. MTC was detected (IS1081IS6110) and resistance to rifampicin was not detected (rpoB1 to 4). MTC is detected by the presence of genes IS 1081 and IS6110. Resistance to rifampicin would be verified if there were mutations in the $r p o B$ gene (1-4). Also included in the cartridge is a sample processing control (SPC) for monitoring the presence of inhibitors in the reaction

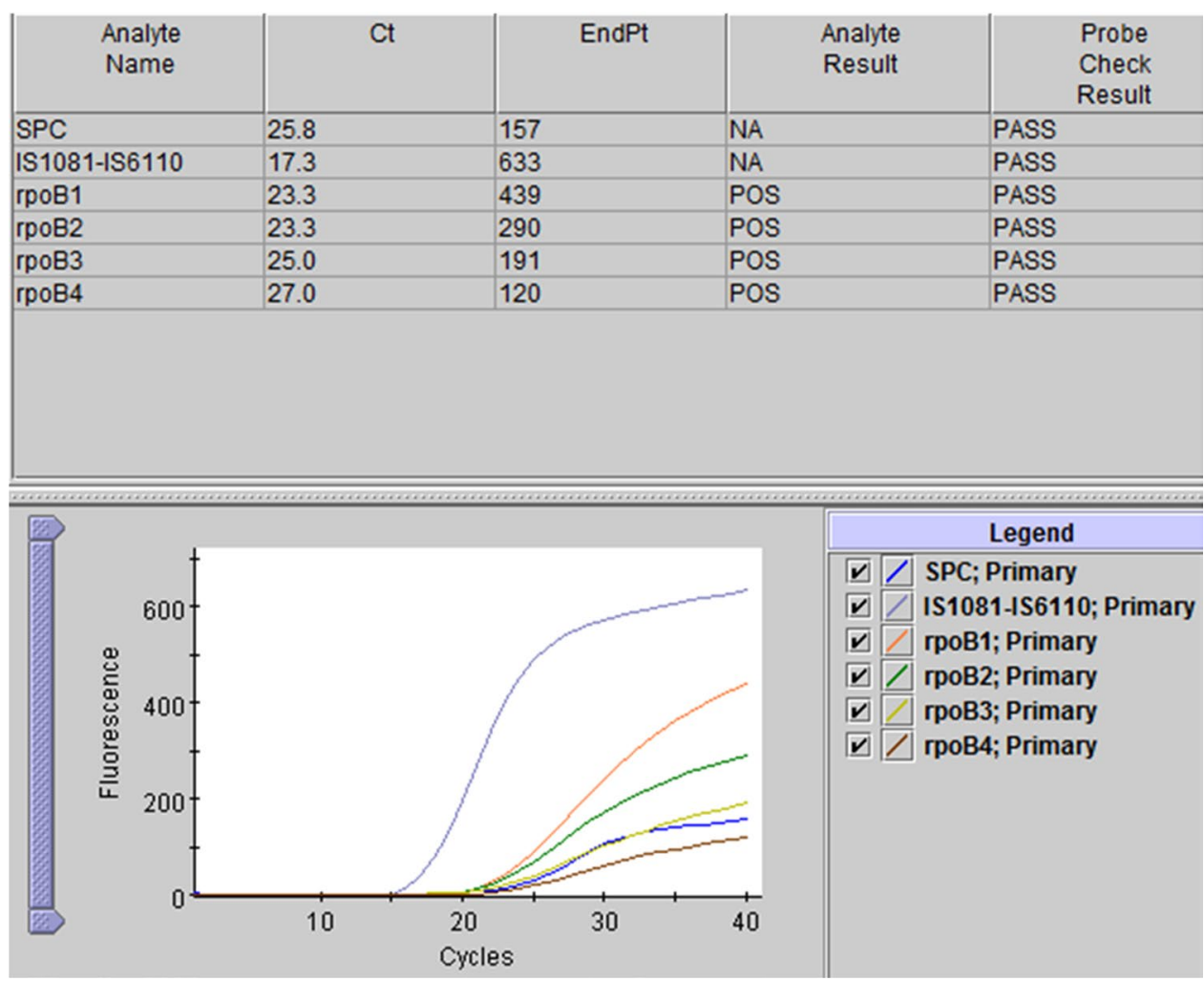


by the Ziehl-Neelsen method, followed by microscopy to verify the culture purity, presence of AFB, and cord formation, which is a presumptive test used to differentiate MTC species from non-tuberculous mycobacteria (NTM) [15].

For the qualitative MTC identification, an immunochromatographic test was used (SD Bioline TB Ag MPT64 rapid ${ }^{\circledR}$, Standard Diagnostic, South Korea), according to the manufacturer's instructions.

The anti-tuberculosis drugs susceptibility was also verified with the phenotypic test in liquid medium using the automated BACTEC MGIT 960® system [16]. For the detection of SARS-CoV-2 in sputum, the GeneXpert platform was used with the Xpert Xpress SARSCoV-2® cartridge (Cepheid, USA). The sputum sample was diluted 1:2 in a sterile saline solution and vortexed until complete liquefaction. Subsequently, $300 \mu \mathrm{L}$ of the liquefied sample was added to the cartridge, which was inserted into the platform following the manufacturer's instructions. To confirm the detection of SARS-CoV-2 in sputum on Xpert Xpress SARS-CoV-2® cartridge, the gold standard RT-qPCR methodology was performed under routine diagnostic conditions. Briefly, both the liquefied sputum sample and the nasopharyngeal secretion sample collected with a combined swab were submitted

Fig. 2 Positive culture in liquid medium using an automated MGIT 960® system Mycobacteria Growth Indicator Tube (Becton \& Dickinson, USA)

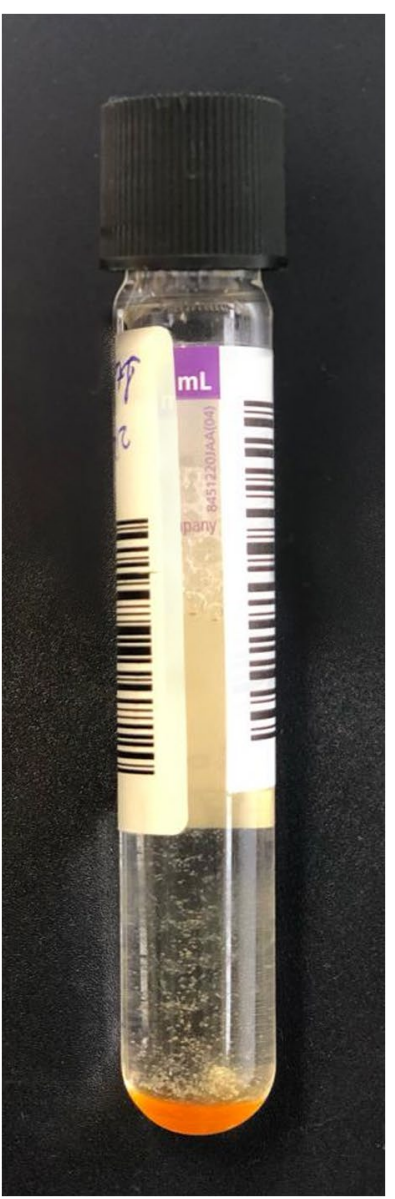

to automatized extraction protocol with magnetic beads (Loccus, Brazil) and the RT-qPCR was performed using the Charite protocol [9], with detection of E, N, and $\mathrm{RdRP} / \mathrm{S}$ genes using the Allplex ${ }^{\mathrm{TM}}$ SARS-CoV-2 Assay (Seegene, South Korea). Amplification curves were analyzed in the QuantStudio ${ }^{\mathrm{TM}}$ Design \& Analysis Software v1.5.1 (Thermo Fisher Scientific, USA).

\section{Results and discussion}

In this study, simultaneous detection of SARS-CoV-2 and MTC in a sputum sample from an individual belonging to the population deprived of liberty was described.

Currently, it has been shown that a variety of biological samples, in addition to nasal and oropharyngeal secretions, may be suitable for the diagnosis of COVID-19. Tianwen et al. (2020) demonstrated a higher sensibility in the detection of SARS-CoV-2 in sputum and a lower rate of false

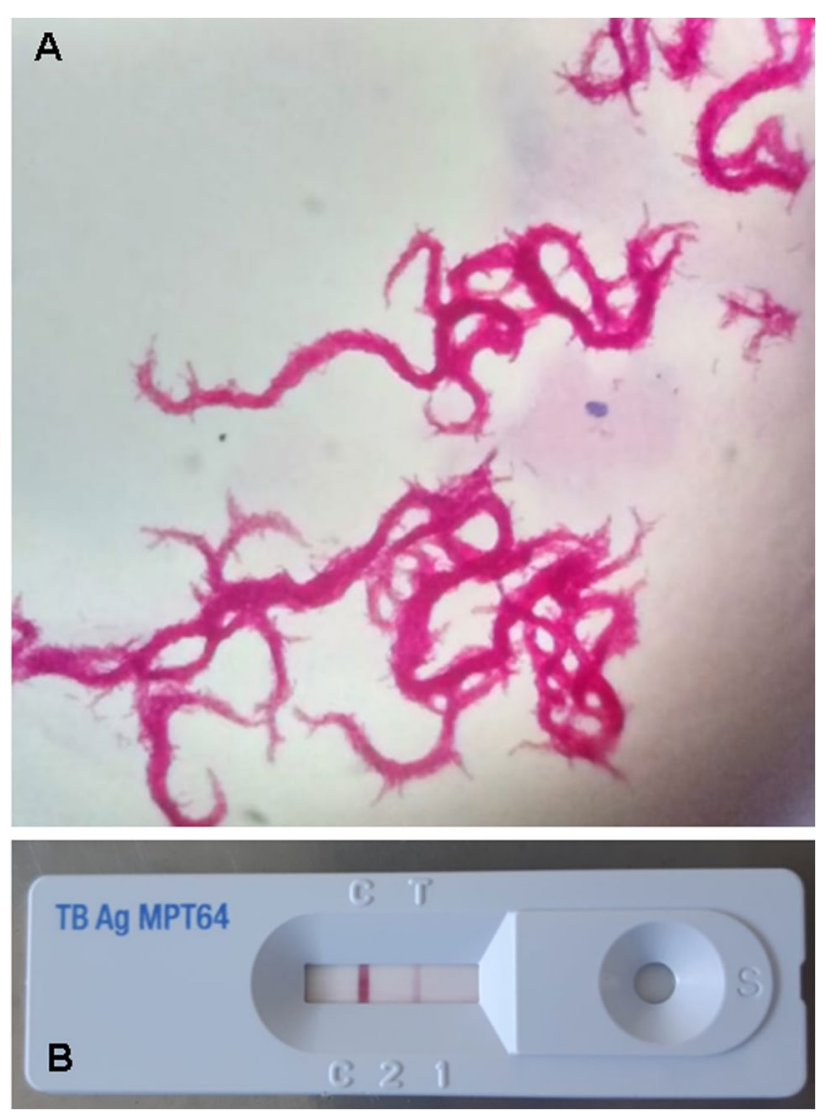

Fig. 3 Presumptive and qualitative identification of MTC. A Culture smear stained by the Ziehl-Neelsen method, followed by microscopy to verify the culture purity, presence of acid-fast bacilli, and formation of structures called "cord factor". B TB Ag MPT64 immunochromatographic test. Antibodies conjugated to gold particles can qualitatively recognize the MTC MPT64 epitope demonstrated by the test line $(\mathrm{T})$ 
negatives than nasopharyngeal smears [8]. However, it is important to highlight few data in the literature using sputum samples with the Xpert Xpress SARS-CoV-2® test for the diagnosis of COVID-19, especially in vulnerable individuals, as well as on comparison between the Xpert Xpress SARS-CoV-2® assay and the RT-qPCR method, the gold standard for the diagnosis of the disease.

The genes IS6110 and IS1081 were detected in the Xpert MTB/RIF Ultra ${ }^{\circledR}$ indicating the presence of MTC, with no mutations in the $r p o B$ gene related to resistance to rifampicin, indicating the susceptibility of the strain (Fig. 1). The result was made available in the laboratory environment management system $2 \mathrm{~h}$ after the sample entered the laboratory.

The detection of MTC was confirmed by culture in liquid medium on an automated system MGIT 960® Mycobacteria Growth Indicator Tube (Becton \& Dickinson, USA) (Figure 2).

The presumptive and qualitative identification of MTC through the cord factor and immunochromatographic test (Figures 3A and B).

The susceptibility test, in the liquid medium, using the automated BACTEC MGIT 960® system, showed sensitive results for the main anti-tuberculosis drugs, rifampicin, and isoniazid (data not shown).

The GeneXpert platform is designed to minimize biological hazards during assay development, as the only manual step consists of sample preparation and addition to the cartridge. Unlike other real-time PCR assays, GeneXpert is a simple technique that can be performed with minimal personal training and provides results in a short period $[10,11]$ at a cost equivalent to other molecular techniques. Tadolini et al. (2020) carried out a study with 49 individuals from different countries with TB/COVID-19 co-infection and found 26 (53.0\%) individuals had MTC infection before COVID-19; 14 individuals (28.5\%) had COVID-19 before TB; and 9 (18.3\%) had both diseases simultaneously, diagnosed in the same week [4]. In the present study, TB/ COVID-19 co-infection was diagnosed in a single sputum sample, using a GeneXpert platform with two different cartridges (Xpert MTB/RIF Ultra ${ }^{\circledR}$ and Xpert Xpress SARSCoV-2®, respectively). Results were available within 80 min for TB (Fig. 1) and 45 min for COVID-19 (Fig. 4).

The presence of SARS-CoV-2 was confirmed in sputum and nasopharyngeal secretion samples by RT-qPCR (Fig. 5A and B).

The first aspect of the TB/COVID-19 co-infection lies in the fact that the symptoms are similar between the two diseases, which may initially make the differential diagnosis difficult [12]. Both TB and COVID-19 may have a worsening clinical picture due to advanced age and the presence of comorbidities, as well as social determinants such as poverty and malnutrition [13].

According to the Brazilian Ministry of Health, the golden standard test to confirm suspected cases of TB is
Fig. 4 Xpert Xpress SARSCoV-2® (Cepheid), with sputum sample. SARS-CoV-2 was detected (E and N2 genes). Also included in the cartridge is a sample processing control (SPC) for monitoring the presence of inhibitors in the reaction

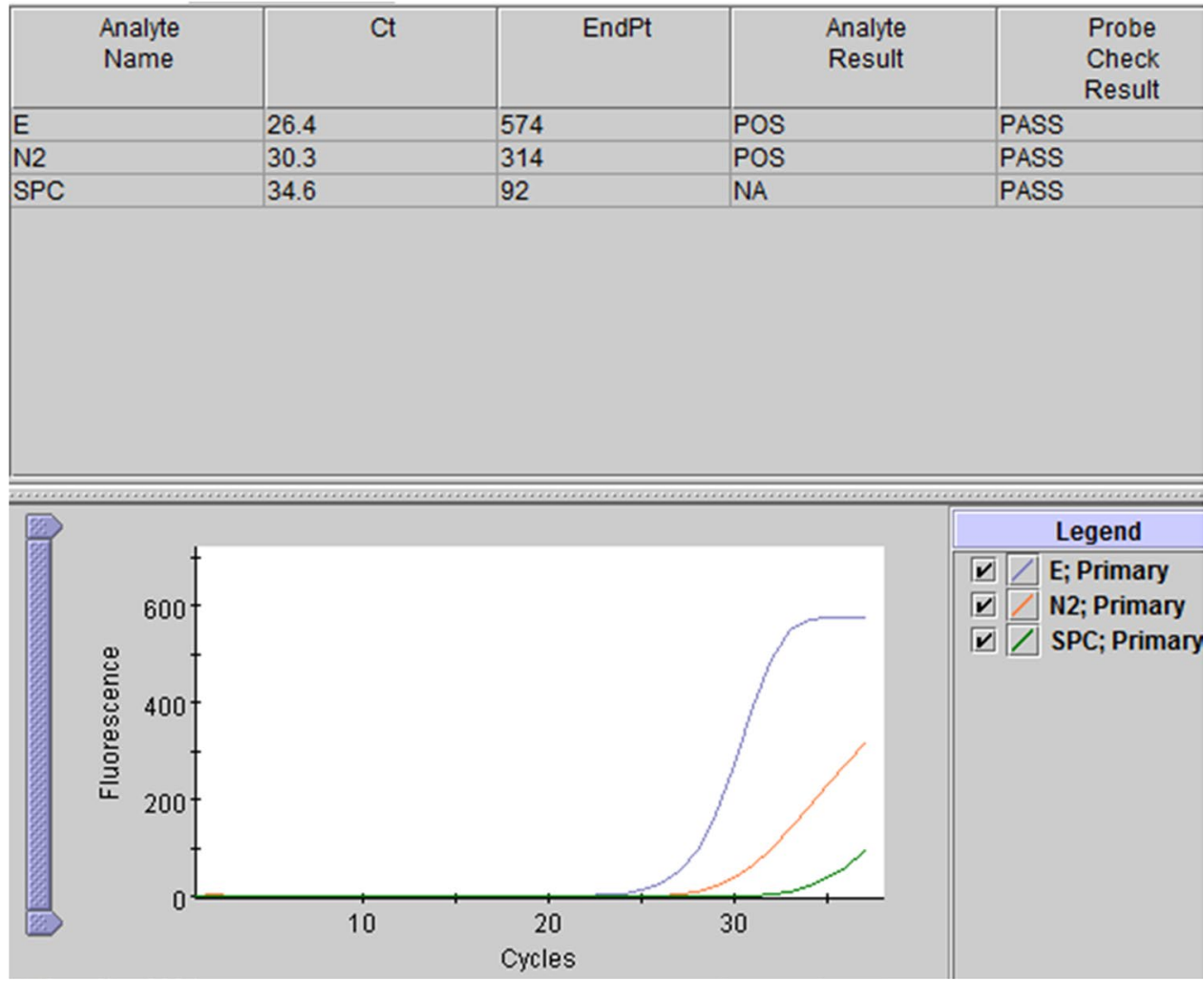


Fig. 5 RT-qPCR with Allplex ${ }^{\mathrm{TM}}$ SARS-CoV-2 Assay (Seegene, South Korea). A Detection of $\mathrm{RdRP} / \mathrm{S}$ genes (orange line, $\mathrm{CT}=24$ ); E gene (yellow line, $\mathrm{CT}=21)$, $\mathrm{N}$ gene (pink line, $\mathrm{CT}=20$ ), and internal control (IC, green line, not analyzed) in sputum sample. B Detection of RdRP/S genes (orange line, $\mathrm{CT}=33$.); E gene (yellow line, $\mathrm{CT}=30$ ), $\mathrm{N}$ gene (pink line, $\mathrm{CT}=31$ ), and internal control (IC, green line, not analyzed) in nasopharyngeal secretion samples
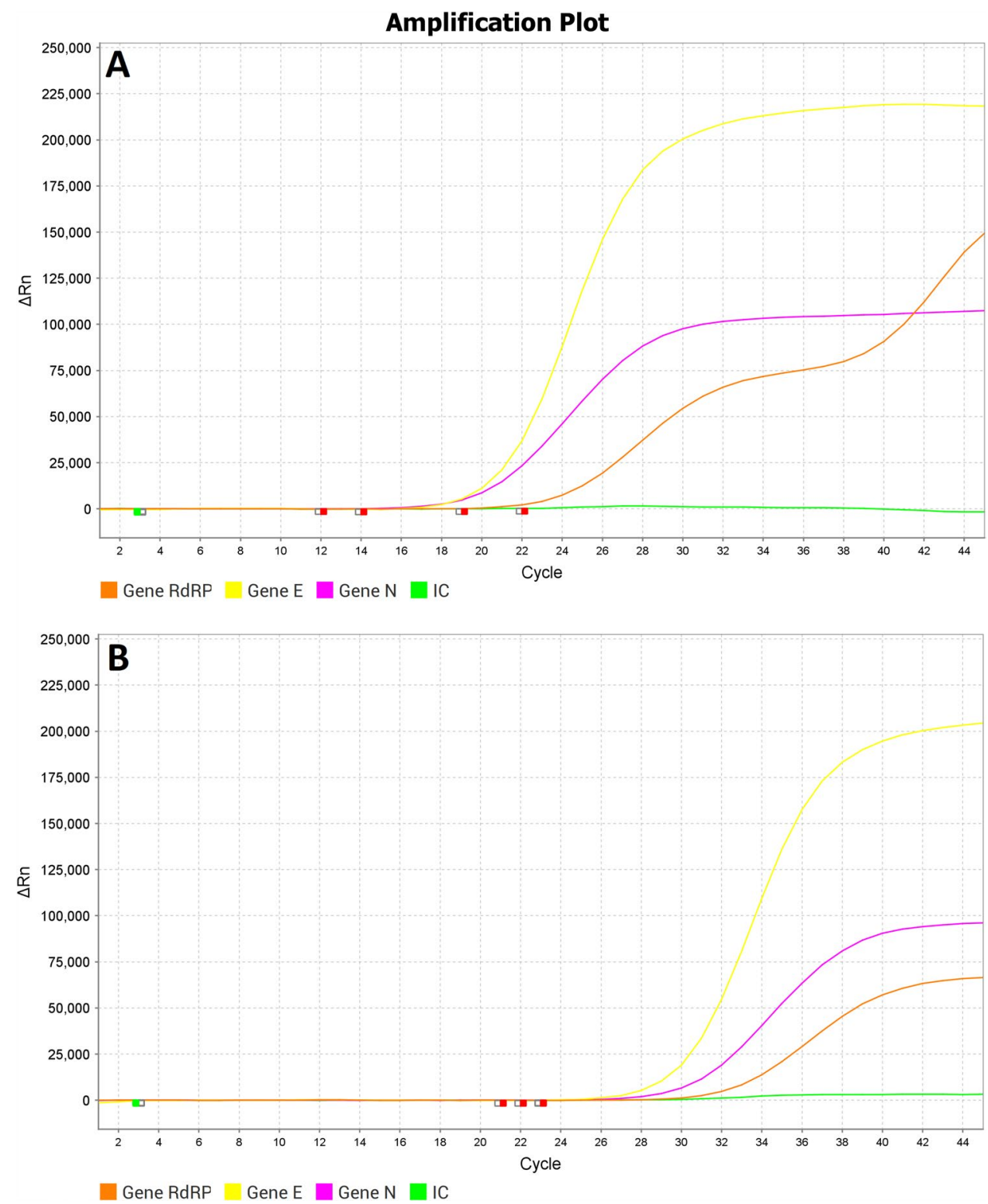

the culture in sputum, while COVID-19 is the RT-qPCR in nasopharyngeal secretion [14, 15]. The Xpert MTB/ RIF Ultra ${ }^{\circledR}$ test is an additional nucleic acid amplification test used for the MTC detection and the screening of antituberculosis drug-resistant genes [11]. The test consists of sample preparation, amplification, and detection of nucleic acids by qPCR with the benefit of the integration and automation of the three processes together, in one cartridge.

\section{Conclusion}

In conclusion, the case presented here demonstrates a diagnostic innovation that is the use of sputum for both diagnoses, TB and COVID-19, using the GeneXpert platform.
It is a simple and fast methodology, with performance and results comparable to the gold standard methodology, capable of accelerating the detection and isolation time of positive patients. In addition, the use of sputum is better, as the presence of a trained professional is not necessary to carry out the collection of specimens, which can avoid the contamination of the health professional during this procedure. Another important point of this work is the evidence that, if the individual was not part of this study, it would not be possible to diagnose the coinfection and, consequently, the infection by SARS-CoV-2 would go unnoticed. Therefore, performing tests on the same sample, simultaneously, can speed up adequate patient care and interrupt the chain of transmission of both diseases. The authors hope that this short communication, that reports a case of TB/COVID-19 
co-infection in an individual belonging to the population deprived of liberty, can help and alert health systems to consider this methodology for implementation in diagnostic practice.

Acknowledgements We are grateful for the support of FAPESP, $\mathrm{CNPq}$, the Brazilian Ministry of Health, and all the professionals involved in this study, from the collection and reception of samples to the performance of the tests. We are also grateful for the technical support of the Center for Epidemiological Surveillance and the Coordination of the Secretariat of Penitentiary Administration, represented by the Provisional Detention Center of the city of Mauá/SP. We also thank the TBSA - Tuberculosis Santo André Working Group: Adriana Gomes da Silva, Ana Paula da Cunha Gonçalves Silva, Marta Dias da Silva and Patricia de Lima Vicente.

Authors' contribution AOG and TRB contributed to sample preparation, performed the Xpert reactions, analyzed the results graphs, and collected the data. DRC and IFR performed the RT-qPCR reactions and analyzed the results graphs. IBC, EC, and MCCN critically revised the manuscript for important intellectual content. VSC and PJSR performed the RNA extractions from sputum and nasopharyngeal secretions. VSMGD facilitated all work-related tasks. AMSC conceived the study, supervised all stages of the work, analyzed the data, wrote the paper, and approved the final draft. All authors contributed to the study, commented on previous versions, and approved the final manuscript.

Funding This study was supported by São Paulo State Research Support Foundation (FAPESP) by grant $\mathrm{n}^{\circ} 2020 / 12124-0$ to AMSC and grant $n^{\circ} 21 / 07098-2$ to TRB.

Data availability All data generated or analyzed during this study are included in this published article.

Code availability Not applicable.

\section{Declarations}

Ethics approval This study was performed in line with the principles of the Declaration of Helsinki. Approval was granted by the Ethics Committee of the Adolfo Lutz Institute, under number CAAE: 39514520.6.0000.0059.

Consent to participate Informed consent to participate was obtained from all individual participants included in the study.

Consent for publication Informed consent for publication was obtained from all individual participants included in the study

Competing interests The authors declare no competing interests.

\section{References}

1. Petersen E, Koopmans M, Go U, Hamer DH, Petrosillo N, Castelli F, et al (2020) Comparing SARS-CoV-2 with SARS-CoV and influenza pandemics. Lancet Infect Dis 20(9):e238-e244 https:// doi.org/10.1016/S1473-3099(20)30484-9

2. Moreira TR, Lemos AC, Colodette RM, Gomes AP, Batista RS (2019) Prevalência de tuberculose na população privada de liberdade: revisão sistemática e metanálise [Prevalence of tuberculosis in incarcerated populations: systematic review and meta-analysis [Prevalencia de tuberculosis en la población privada de libertad: revisión sistemática y metanálisis]. Rev Panam Salud Publica 43:e16. Portuguese https://doi.org/10. 26633/RPSP.2019.16

3. Sy KTL, Haw NJL, Uy J (2020). Previous and active tuberculosis increases risk of death and prolongs recovery in patients with COVID-19. Infect Dis (Lond) 52 (12):902-907 https://doi. org/10.1080/23744235.2020.1806353.

4. Tadolini M, Codecasa LR, García-García JM, Blanc FX, Borisov S, Alffenaar JW, Andréjak C, Bachez P, Bart PA, Belilovski E, Cardoso-Landivar J, Centis R, D'Ambrosio L, Luiza De Souza-Galvão M, Dominguez-Castellano A, Dourmane S, Fréchet Jachym M, Froissart A, Giacomet V, Goletti D, Grard S, Gualano G, Izadifar A, Le Du D, Marín Royo M, Mazza-Stalder J, Motta I, Ong CWM, Palmieri F, Rivière F, Rodrigo T, Silva DR, Sánchez-Montalvá A, Saporiti M, Scarpellini P, Schlemmer F, Spanevello A, Sumarokova E, Tabernero E, Tambyah PA, Tiberi S, Torre A, Visca D, Zabaleta Murguiondo M, Sotgiu G, Migliori GB (2020) Active tuberculosis, sequelae and COVID-19 co-infection: first cohort of 49 cases. Eur Respir J 56(1):2001398 https://doi.org/10.1183/13993003.01398-2020

5. Motta I, Centis R, D’Ambrosio L, García-García JM, Goletti D, Gualano G, Lipani F, Palmieri F, Sánchez-Montalvá A, Pontali E, Sotgiu G, Spanevello A, Stochino C, Tabernero E, Tadolini M, van den Boom M, Villa S, Visca D, Migliori GB (2020) Tuberculosis, COVID-19 and migrants: preliminary analysis of deaths occurring in 69 patients from two cohorts. Pulmonology 26(4):233-240. https://doi.org/10.1016/j.pulmoe.2020.05.002

6. Liu Y, Bi L, Chen Y, Wang Y, Fleming J, Yu Y, et al. (2020) Active or latent tuberculosis increases susceptibility to COVID19 and disease severity. medRxiv https://doi.org/10.1101/2020. 03.10 .20033795

7. Wölfel R, Corman VM, Guggemos W, Seilmaier M, Zange S, Müller MA, Niemeyer D, Jones TC, Vollmar P, Rothe C, Hoelscher M, Bleicker T, Brünink S, Schneider J, Ehmann R, Zwirglmaier K, Drosten C, Wendtner C (2020) Virological assessment of hospitalized patients with COVID-2019. Nature 581(7809):465469. Erratum in: Nature Dec;588(7839): E35 https://doi.org/10. 1038/s41586-020-2196-x

8. Lai T, Xiang F, Zeng J, Huang Y, Jia L, Chen H, Wu J, Xie J, Liu S, Deng W, Zheng W, Huang Y, Zhang Q, Luo Q, Mo F, Long L, Zhang W, Chen W, Han H (2020) Reliability of induced sputum test is greater than that of throat swab test for detecting SARSCoV-2 in patients with COVID-19: a multi-center cross-sectional study. Virulence 11(1):1394-1401 https://doi.org/10.1080/21505 594.2020 .1831342

9. Corman VM, Landt O, Kaiser M, Molenkamp R, Meijer A, Chu DK, Bleicker T, Brünink S, Schneider J, Schmidt ML, Mulders DG, Haagmans BL, van der Veer B, van den Brink S, Wijsman L, Goderski G, Romette JL, Ellis J, Zambon M, Peiris M, Goossens H, Reusken C, Koopmans MP, Drosten C (2020) Detection of 2019 novel coronavirus (2019-nCoV) by real-time RT-PCR. Euro Surveill 25(3):2000045. Erratum in: Euro Surveill. 2020 Apr;25(14): Erratum in: Euro Surveill. $2020 \mathrm{Jul}$;25(30): Erratum in: Euro Surveill. $2021 \mathrm{Feb}$;26(5) https://doi.org/10.2807/15607917.ES.2020.25.3.2000045

10. Agência Nacional de Vigilância Sanitária; Agência Nacional de Saúde Suplementar; Brasil (2011) Xpert® MTB/RIF no diagnóstico da tuberculose pulmonar. BRATS: Boletim Brasileiro de Avaliação de Tecnologias em Saúde; 6 (16). ISSN 1983-7003. Article in Portuguese. https://docs.bvsalud.org/biblioref/2019/04/ 994588/brats_16.pdf

11. Dorman SE, Schumacher SG, Alland D, Nabeta P, Armstrong DT, King B, Hall SL, Chakravorty S, Cirillo DM, Tukvadze N, Bablishvili N, Stevens W, Scott L, Rodrigues C, Kazi MI, Joloba 
M, Nakiyingi L, Nicol MP, Ghebrekristos Y, Anyango I, Murithi W, Dietze R, Lyrio Peres R, Skrahina A, Auchynka V, Chopra KK, Hanif M, Liu X, Yuan X, Boehme CC, Ellner JJ, Denkinger CM; study team (2018) Xpert MTB/RIF Ultra for detection of Mycobacterium tuberculosis and rifampicin resistance: a prospective multicentre diagnostic accuracy study. Lancet Infect Dis. 18(1):76-84. Erratum in: Lancet Infect Dis 2018 Feb 21; https:// doi.org/10.1016/S1473-3099(17)30691-6

12. Vanzetti CP, Salvo CP, Kuschner P, Brusca S, Solveyra F, Vilela A (2020). Coinfección tuberculosis y COVID-19 [Tuberculosis and COVID-19 coinfection]. Medicina (B Aires) 80 Suppl 6:100-103. Spanish

13. Visca D, Ong CWM, Tiberi S, Centis R, D’Ambrosio L, Chen B, Mueller J, Mueller P, Duarte R, Dalcolmo M, Sotgiu G, Migliori GB, Goletti D (2021) Tuberculosis and COVID-19 interaction: A review of biological, clinical and public health effects. Pulmonology 27(2):151-165. https://doi.org/10.1016/j.pulmoe.2020.12.012

14. Ministério da Saúde. Secretaria de Ciência, Tecnologia, Inovação e Insumos Estratégicos em Saúde (2020) Diretrizes para Diagnóstico e Tratamento da COVID-19. Versão 4. Article in Portuguese. https://pncq.org.br/uploads/2020-1/Diretriz-Covid19-v4-07-05. $20 \mathrm{~h} 05 \mathrm{~m} . \mathrm{pdf}$
15. Ministério da Saúde. Secretaria de Vigilância em Saúde. Brasil (2008) Manual Nacional de Vigilância Laboratorial da Tuberculose e Outras Micobactérias. $1^{a}$ edição; ISBN 978-85-334-1447-1. Article in Portuguese. https://bvsms.saude.gov.br/bvs/publicacoes/ manual_vigilancia_laboratorial_tuberculose.pdf

16. Ardito F, Posteraro B, Sanguinetti M, Zanetti S, Fadda G (2001) Evaluation of BACTEC Mycobacteria Growth Indicator Tube (MGIT 960) automated system for drug susceptibility testing of Mycobacterium tuberculosis. J Clin Microbiol 39(12):4440-4444. https://doi.org/10.1128/JCM.39.12.4440-4444.2001

Publisher's Note Springer Nature remains neutral with regard to jurisdictional claims in published maps and institutional affiliations.

\section{Authors and Affiliations}

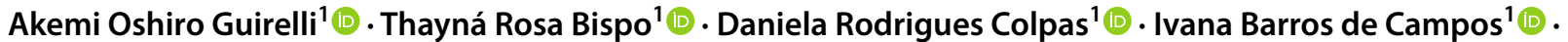 Erica Chimara ${ }^{2}$ (D) Maria Cecília Cergole-Novella ${ }^{1}$ - Itatiana Ferreira Rodart ${ }^{1}{ }^{10}$.

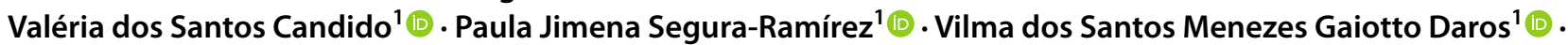 Andreia Moreira dos Santos Carmo ${ }^{1}$}

\author{
Akemi Oshiro Guirelli \\ akemi.guirelli@ial.sp.gov.br \\ Thayná Rosa Bispo \\ thaynarosabispo15@gmail.com \\ Daniela Rodrigues Colpas \\ daniela.colpas@ial.sp.gov.br \\ Ivana Barros de Campos \\ ivanacamp@gmail.com \\ Erica Chimara \\ erica.chimara@ial.sp.gov.br \\ Maria Cecília Cergole-Novella \\ maria.novella@ial.sp.gov.br \\ Itatiana Ferreira Rodart \\ irodart@gmail.com
}

\author{
Valéria dos Santos Candido \\ valeria.candido@ial.sp.gov.br \\ Paula Jimena Segura-Ramírez \\ paulasegura64@gmail.com \\ Vilma dos Santos Menezes Gaiotto Daros \\ vilma.daros@ial.sp.gov.br \\ 1 Santo André Regional Center, Adolfo Lutz Institute, \\ Av Ramiro Colleoni, 240 - Vila Dora, Santo André, \\ SP Zip Code 09040-160, Brazil \\ 2 Adolfo Lutz Institute, Av Dr Arnaldo, 355 - Pacaembu, \\ São Paulo, SP Zip Code 01246-902, Brazil
}

